\title{
Evaluation and Optimization on Knowledge Value Chain of Enterprises in the Logistics Park
}

\author{
Rongli Shi \\ School of Medical Business of Guangdong Pharmaceutical University, Guangdong Province, China \\ Isemail2008@163.com
}

Keywords: Logistics park, Knowledge value chain, Value chain optimization, Analytic hierarchy process(AHP), Fuzzy comprehensive evaluation method.

\begin{abstract}
Enterprises in logistics park in the period of logistics park adjustment and transition, began to look to the development of enterprise knowledge value chain. In this paper, the basic activities and auxiliary activities of the knowledge value chain of enterprise in logistics park were analyzed, and combining with the analytic hierarchy process and fuzzy comprehensive evaluation method, given the knowledge value chain optimizing strategy of the process reengineering, knowledge network and policy matching, to give help to the development of enterprise in logistics park.
\end{abstract}

\section{Introduction}

The value chain is a basic tool to analyze the core competitiveness of enterprises, it is a systematic method of enterprise competitive advantage; combination of various value activities of enterprises in the production process in the form of the enterprise value chain. In the same industry, different enterprise value chain is the important source of core competence. In order to enable enterprises to obtain and maintain competitive advantage, enterprises need according to the changing environment and own conditions for its value activities from the quantity, quality, time to make reasonable adjustments, and to achieve the optimization of the value chain to. Because knowledge is the core element of logistics enterprises, which is the core of enterprise knowledge value chain logistics value chain. Knowledge value chain theory is accompanied by the development of knowledge economy and the formation of the basic activity; knowledge value chain enterprise with value chain are similar, with the enterprise value network flow formed, produce, development. Knowledge value chain is actually composed of knowledge chain and value chain, the interweaving effect, promote enterprise capital appreciation, and the formation of new operation mode of enterprises in knowledge economy era.

Value chain model based on Michael Potter, scholars have tried to make the enterprise value chain and knowledge elements are combined effectively, become a more realistic management theory. Peng Rui[1] from the main activities of the value chain of knowledge and auxiliary activities of knowledge value chain model, provides the theory basis for enterprises to cultivate the core competence. Hong Jiangtao[2] from the point of view of knowledge development enterprise value chain optimization for enterprises to keep sustainable competitive advantage of an in-depth research, and the research scope to enterprise's external value chain optimization. Chen Chunhua[3] thinks, knowledge transfer and business process between the relevant departments, and the knowledge value chain is the effective way to combine the two. At present, research on the logistics industry or enterprise value chain is still relatively small.

\section{Analysis of Enterprise Knowledge Value Chain Theory of Logistics Park}

Knowledge value chain is a series of can bring economic benefits to the enterprise knowledge activities in aggregate, reflected in the production and sales of various links. The theory of value chain and Michael Potter will be the value of the business activities are divided into two categories: one category is the basic activity, plays a fundamental role in the development of enterprises, mainly in internal logistics, production, sales, customer service, external logistics service; one is auxiliary 
activities, plays a supporting role in it on the development of enterprises, enterprises have the infrastructure, human resources management, technology development, procurement. The knowledge value activities of enterprise logistics park, we will form the core competence of knowledge management activities play a key role in two categories. Its basic activities are centered on knowledge management process of the formation, including logistics, logistics, logistics, logistics evaluation of the sales; auxiliary activities around the factors of knowledge management supporting conditions and other effects of talent management, including logistics, logistics, logistics resources protection setting.

Basic Activities. Basic activities refers to the related products and sales material creation, transfer to the buyer and customer service activities. The basic activities of knowledge value chain enterprise logistics park is the most fundamental value chain management tasks. It is the basic process of formation, knowledge elements of enterprise application and value creation, transfer, implementation.

1)Logistics Form: The logistics park enterprises differentiated competitive advantage, companies should be based on the pursuit of customer value realization process, to provide customers better than the competition and are not easily imitated by competitors products. Therefore, the logistics is the core business of the logistics park is to retain competitive differentiation premise. Customer value-oriented enterprise to manage the enterprise's business activities, its meaning in the pursuit of customer satisfaction and loyalty, so that enterprises can provide sustained competitive differentiation. Logistics is the logistics parks business knowledge resources for the carrier, logistics knowledge through a series of activities, causing part of the value added production and consumption of flexible units.

2) Logistics Applications: Logistics is the process of application for enterprise logistics operations among the results and strengthen their core competence. Logistics companies will commercialize the knowledge to make customers feel as much cultural knowledge logistics charm. Logistics knowledge is that people will act on their own creativity substance, the product has a more heterogeneous, more acceptable to the client.

3) Logistics Sales: Compared with the enterprise logistics park in the traditional enterprise logistics park, with the market needs it more effectively docking, from traditional sales methods also need a seller's market into a buyer's market, you need to take the "introduction - going out" strategy, access market recognition. Companies need to change their thinking, that is, from traditional corporate pursuit of profit maximization great change to meet customer needs, so that they get the maximum value.

4) Logistics Evaluation: Assess the results of the logistics business through customer feedback to measure customer satisfaction, divided into four levels: very satisfied, satisfied, satisfied, dissatisfied. Through these four levels, logistics companies can be a good assessment of the logistics satisfied with brute force protection, satisfaction and more satisfied with the further development of the logistics required to make them satisfied over the logistics, and for dissatisfied logistics transformation performed reasonably identify the reasons for their dissatisfaction, if it continues to develop, the need to be guided; without considering the continued development, the need for timely abandoned.

Customer satisfaction with the outcome of the logistics and customer expectations are inseparable, to customers through its logistics experience expected by comparing results of customer satisfaction.

Auxiliary Activities. Auxiliary activities refer to the basic activities to provide technology, human resources and a variety of company wide functions and a series of activities. Auxiliary activities of knowledge value chain, is not directly involved in the process of logistics from the access to basic operation of logistics applications, but the main activities of the logistics management to support, guide and standardize the activities. Although they construct the core competence of the enterprise, do not have a direct impact, but they are necessary for the successful organization of logistics management.

1) Logistics Talent Management: Logistics personnel management is important to support the healthy development of logistics enterprises in the park. Development of the logistics park enterprise, talent is the most important input factors, it gives injected vitality into the development of enterprises. 
However, most companies have not done enough for talent management, the lack of a long-term management personnel mechanism, which resulted in a large number of logistics personnel turned to other logistics areas. Huge loss of talent is one of the most enterprise logistics parks should solve the problem. Enterprises can be to strengthen the logistics personnel management: establish reasonable and effective incentive mechanism; provide a comfortable working environment; apply flexible working; solve their children's education and spouse employment and other practical problems.

2) Establish a Logistics Environment: Establish logistics environment is a powerful guarantee the healthy development of logistics enterprises in the park. Soft environment, including enterprise and scientific management, the formation of corporate culture, the establishment of relevant enterprise system, such as the overall quality of staff, they facilitate the formation of core values. Hard environment including sound (such as production tools and equipment, transportation, etc.) enterprise infrastructure, research and development of new materials, logistics, improvement, financing channels, such as the diversity of the production process, for enterprises to develop their knowledge and innovation, further development has provided a guarantee .

3) Logistics Resource Conservation: Protection of logistics resources is the key to the healthy development of logistics enterprises in the park. Logistics is the integration of people of knowledge and real crystal, into logistics personnel for their hard work, is not unlawful theft. Enterprise logistics park can be several ways to effectively protect the logistics resources: patent application and protection; permission transaction management; security of information systems.

\section{Enterprise Knowledge Value Chain Evaluation of Logistics Park}

Hierarchy Structure Model of Knowledge Value Chain. The analytic hierarchy process (AHP) is a multi-criteria decision making method, to qualitative and quantitative factors in decision making process. As shown in Table 1, this paper constructs the enterprise knowledge value chain logistics park in the hierarchical structure model.

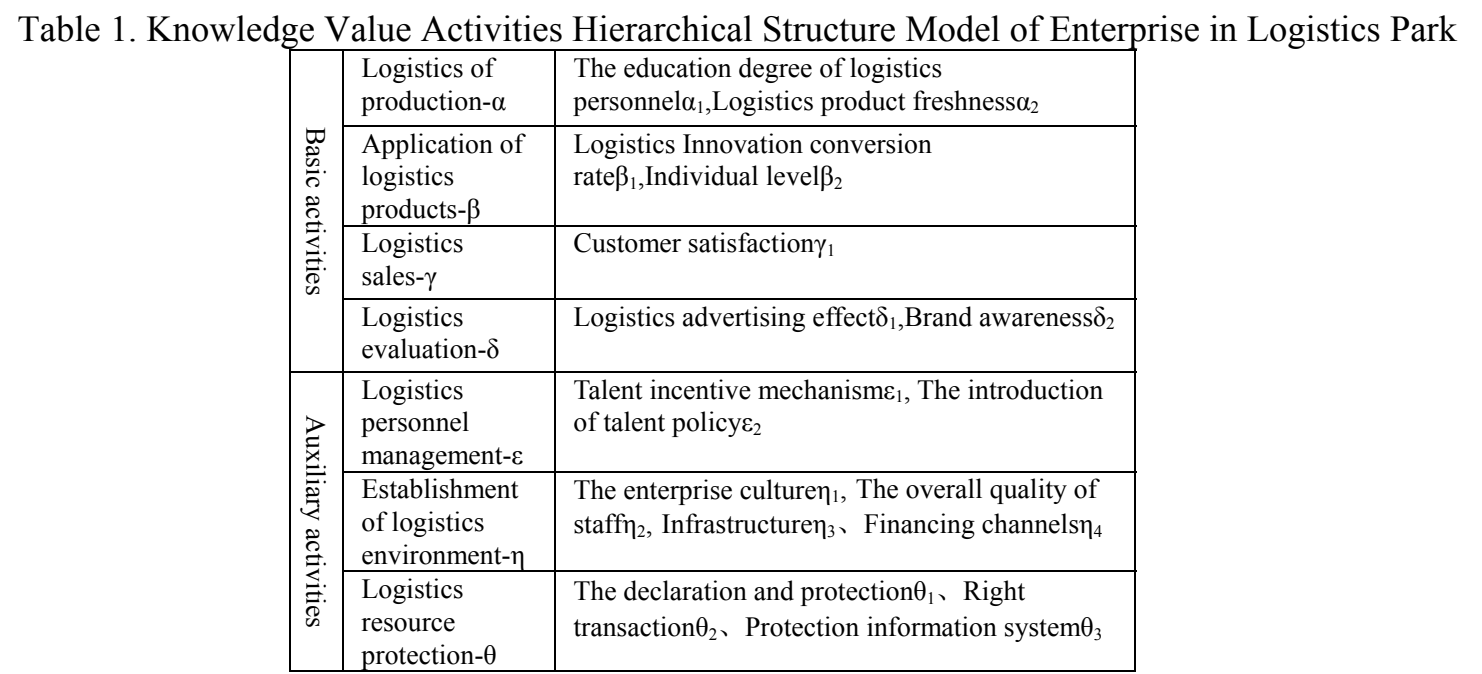

Construction of Judgment Matrix. This paper constructs the judgment matrix according to the principle of AHP, through the calculation of: $\lambda_{\max }=2$, the consistency test, meet the requirements. The weights are a $1=0.75$, a $2=0.25$. As shown in Table 2 , due to the large number of judgment matrix, to avoid repetition, appear in the waste of resources, the other is no longer listed. 
Table 2. The Relative Weight of Each Index

\begin{tabular}{|l|l|}
\hline$\alpha=0.305$ & $\alpha_{1}=0.75, \alpha_{2}=0.25$ \\
\hline$\beta=0.292$ & $\beta_{1}=0.55, \beta_{2}=0.45$ \\
\hline$\gamma=0.216$ & $\gamma_{1}=1$ \\
\hline$\delta=0.187$ & $\delta_{1}=0.517, \delta_{2}=0.483$ \\
\hline$\varepsilon=0.405$ & $\varepsilon_{1}=0.375, \varepsilon_{2}=0.625$ \\
\hline$\eta=0.316$ & $\eta_{1}=0.303, \eta_{2}=0.281, \eta_{3}=0.223, \eta_{4}=0.193$ \\
\hline$\theta=0.279$ & $\theta_{1}=0.402, \theta_{2}=0.273, \theta_{3}=0.325$ \\
\hline
\end{tabular}

According to table 2 results can be used to calculate the combined weight of 16 evaluation indexes:

$\mathrm{W}=(0.229,0.076,0.161,0.131,0.216,0.097,0.090,0.152,0.253,0.096,0.089,0.070,0.061,0.112,0.07$ $6,0.091)$

Value Activity on Fuzzy Comprehensive Evaluation. We can divide the 16 factors that influence enterprise logistics park construction as the evaluation factor set U, and the excellent, good, general and poor, five kinds of evaluation results. The evaluation set $\mathrm{V}$. We invited 40 experts to have in-depth study on the value of logistics activities to carry on the evaluation to the relevant enterprises, get the following evaluation matrix:

A mathematical model of the fuzzy comprehensive evaluation: $B=W \cdot R$, $\mathrm{B}=(0.177,0.292,0.783,0.570,0.177)$, normalized $\mathrm{B}^{\prime}=(0.089,0.146,0.391,0.285,0.089)$. Remember the evaluation set is the result of comprehensive evaluation score of $V=(95,80,60,40,15)$, $\mathrm{G}=\mathrm{B}^{\prime} \cdot \mathrm{VT}=56.33$, enterprise logistics park's assessment is " moderate", the development of the knowledge value chain remains to be improved. Although the customer satisfaction, logistics enterprise logistics park has a higher management is in place, but the logistics resource conservation efforts are not enough, logistics, advertising effect is not high, a single enterprise product awareness needs to be improved, but also the need to further improve the logistics environment.

\section{Conclusions}

Through the above analysis, we can draw the conclusion: the development of enterprises in the logistics park for the development of logistics product, is of great benefit. It not only solved the problem of excess capacity, restricting economic development problems of traditional logistics, and enhance the industry position, the traditional logistics to regain its former glory. As people consumption level rise increasingly, people pursuit of logistics quality is also growing, logistics products accounted for their daily consumption expenditure proportion is also growing, which provides a good opportunity for the development of logistics industry. But its development is also faced with the threat from all sides, for example, the shortage of funds, lack of talents, infrastructure is not perfect, intellectual property rights protection and the lack of foreign competition, which will restrict the development of logistics park. To reduce these threats, need between the enterprise and enterprise, enterprise and government, enterprise and customer knowledge collaboration, make knowledge flow, information flow, material flow, capital flow can be a very good flow, knowledge value network suitable for enterprise development.

\section{References}

[1] Peng Rui, "Construction of core competence: knowledge value chain model," Economic Management, Vol.18,pp. 20-25,2013.

[2] Hong Jiangtao, "Review of the research on the value chain and the optimization theory," Journal of China University of Geosciences (SOCIAL SCIENCE EDITION), Vol.1,pp.90-95,2009.

[3] Chen Chunhua, "Research on knowledge value chain model of modern," Management Knowledge Transfer, Vol.10,pp.109-111,2010. 